\title{
A Phenomenological Study on Students' Experiences in Learning Physics in an Online Class
}

\author{
Justine C. Mercado* \\ Department of Natural Science and Mathematics, Notre Dame of Marbel University, Alunan Avenue, Koronadal City, Philippines
}

*Corresponding Author: jcmercado@ndmu.edu.ph

\section{ABSTRACT}

Online learning keeps on growing and being explored during this pandemic. Most of the tertiary institutions here in the Philippines have shifted from face-to-face to online instructions in all courses including physics subjects. The conduct of physics classes through virtual classrooms has its advantages and presents some challenges that are why it is important to understand the perspective and experiences of students. This study aimed to describe the experiences of students in learning physics in a virtual classroom, specifically their experiences in preparation, learning management, opportunities, and challenges they have encountered. There were four themes that emerged in this study: Technological Preparations, Self-Preparations, Challenges in Online Learning, and Leaning Management and Opportunities. It was realized in this study that students were prepared to take online classes both in terms of their technological and personal aspect. Despite their preparations, they encountered challenges such as network issues, time constraints, and distractions in their learning environment at home. However, students were optimistic, so, they saw opportunities in these challenges to improve their technological skills, time management, and maximized online resources for better understanding of physics concepts. It is recommended for future research to explore the experiences of teachers in teaching online physics classes.

KEY WORDS: Online class; physics teaching; science students; COVID-19 pandemic; lived experiences

\section{INTRODUCTION}

○ The growth of online learning has increased drastically due to the coronavirus disease (COVID-19) pandemic caused by the virus severe acute respiratory syndrome coronavirus 2 (SARS-COV-2). This pandemic has challenged the educational system across the world and forced many higher education institutions (HEIs) to shift from traditional pedagogical methods to more online teaching and learning. During the earlier months of the outbreak here in the Philippines, the Commission on Higher Education (CHED) released a memorandum ordering HEIs to exercise academic freedom and take necessary actions to secure students' safety (CHED, 2020). Hence, schools were forced to suspend face-to-face classes, close temporarily, and opt for a flexible learning approach. This shift in the education instructional delivery was caused by the fear that HEIs would lose the whole ongoing semester or even more in the coming future. Due to this sudden change, the educators and students adjusted a lot to adapt to this new normal education, affecting their performances, day-to-day life, and even their education perceptions, especially in science education.

Science education is one of the most critical subjects at the secondary and tertiary level due to its relevance to students' lives and the universally applicable problem-solving and critical thinking skills it uses and develops (Arrieta et al., 2020). These lifelong skills allow students, especially science majors, to generate ideas, weigh decisions intelligently, understand the concepts and theory behind certain phenomena, and be able to share with others. The teaching of problem-solving and critical thinking skills to students help them succeed in school and beyond. Science education, specifically for this study physics education, is about teaching and learning that involves students in an inquiry-based investigation in which they interact with teachers and peers; establish connections between current knowledge and scientific understanding and then apply them through experimentation; engage in problem-solving, planning, and reasoning from evidence; and enable students to experience an active learning approach (Contant et al., 2018).

I would argue that physics learning is better when there is an exposure of students to the outside world that is beyond the classroom. Through these exposures of students to the outside world as well as performing laboratory experimentations, students can apply and better grasp physics concepts (Mercado, 2020). However, in this pandemic, these exposures to the outside world and actual laboratory experimentation were not allowed as advised by our CHED. Furthermore, this is a safety measure of the institutions to protect their student and employees from being exposed and infected by the SARS-CoV-2 virus. Hence, the conduct of the physics classes and science classes, in general, was done through different modalities such as modular distance learning, television/radio-based instructions, blended learning, and online distance learning (Philippine Information Agency, 2020). 
Online education and e-learning are not a new approach in the field of education. It addresses many issues in delivering instruction, such as geographical remoteness, a limited offering by institutions, and students' complex lives (Clarke et al., 2008) even before the pandemic. Learning science in an online environment offers an "anytime and anywhere" education for both students and teachers pursuing graduate programs (Obbink and Wheeler, 1993). According to Gedera et al. (2015), online education offers many opportunities for flexibility, collaboration, and interaction that are way different from the face-to-face learning environment. One difference is the use of educational technologies to design, deliver, manage learning, and knowledge imparting at anytime and anywhere.

The use of gadgets such as computers, cellphones, and tablets together with online video conferencing platforms enables students to still have new practices, experiences, and opportunities in terms of learning science even during this pandemic. However, this new mode of instructional delivery posed a lot of questions to the academic leaders, such as; what do students think about online learning? What do students do to be successful in online learning? and What can be done to improve student's access to this type of learning? These questions are essential to sustain the enrollment numbers in schools and determine the future implications to the education sector (Nwankwo, 2015). It is also integral that in the conduct of online classes, the experiences, sentiments, and perceptions of students must be identified so that necessary improvements can be made (Rodriguez et al., 2008). Students' perceptions about online learning are not all positive. According to Goodall et al. (2005), online learning may cause inadequate human interaction needed to establish peer support, limit more profound discussion on the subject matter, as well as connectivity problems that add to the difficulty of the subject matter. On the other hand, students expressed that online learning made them more responsible and held greater accountability for their learning.

In spite of the significant growth and interest in online learning or e-learning, positive outcomes are not ensured in all contexts (Gedera, 2014). With this, some of the research findings have shown that there are uncertainties about teaching and learning online. In the study of Blackmon and Major (2012), the students who took online distance learning experienced connectivity loss, instructor inaccessibility, autonomy in learning, and lesser peer interaction. On the other hand, online learning affects the academic performances of students and changes in attitude and habits. In the study of Fjelstul (2006) and Salamat et al. (2018), online mode of instruction helped students' academic performance to improve and become motivated to attend class; however, Zhu et al. (2013) stated that despite the positive effects of e-learning on academic performance, students' attitudes and perceptions toward online learning are very unpredictable, and students may manifest many possible undesirable habits. Therefore, online learning impacts on learning physics need to be explored.
Classes for the school year 2020-2021 in the private HEI in Koronadal City last opened August 24, 2020, and have continue to opt for online distance learning. Since the pandemic started, the school has not been able to conduct any face-to-face classes, to include physics. What are the experiences of these physics students in terms of their preparation, learning engagement, and perceived challenges in online learning? This study sought to explore and gain insight from these students' experiences in learning physics in this time of pandemic. The experiences and perceptions of students that can be drawn out from this study can be a basis to improve the teaching and learning of physics using online platforms.

\section{Purpose of the Study}

The main purpose of this study was to explore, describe, and gain insights from the experiences of Bachelor of Secondary Education (BSED) major in science students in learning physics through online platforms.

\section{METHOD}

\section{Research Design}

To explore the experiences of the students in learning physics in this new normal, the study utilized a Descriptive Phenomenological Research Design. Phenomenological design is a type of qualitative research that deals with the similarities of a lived experience in a particular group. The aim of this design is to arrive at a description of a certain phenomenon (Cresswell, 2013).

\section{Sampling Design}

The informants of this study were 10 BSED science students which enable the researcher to have a rich data to be analyzed. They were chosen purposively because the study is specific to a certain phenomenon only (Lopez and Whitehead, 2013), and the selection criteria were as follows: (1) The students should be enrolled under BSED science program, school year 2020-2021 and (2) have taken physics courses during the 2020-2021 school year through online distance learning.

\section{Data Collection and Instrumentation}

Experts in educational management, curriculum, and assessment were asked to validate the in-depth interview guide. After the validation process, the researcher modified as necessary, such as the way, the questions were asked and constructed that would allow students to answer the statement of the problem. Then, the researcher wrote a letter to the academic vice president of the institution to ask permission to conduct the study and secure certification from the research ethic committee. Another letter was sent to the informants through email or other platforms to inform them that they were being invited to participate in the study. After receiving the confirmation of the informants, they signed a letter of consent before the interview to assure that their participation in the study was voluntary. These participants agreed to state their experiences during the interview process and that these experiences would be used in this research and were assured 
that their participation and responses would not affect their academic status in any of their subjects. After the signing of the letter of consent, participants were briefed about the mechanism and purpose of the interview. This study used audio recording to record the interview to facilitate the transcription of the interview for data analysis.

\section{Data Analysis}

The data were analyzed using Colaizzi's (1978) strategy. Colaizzi's seven procedural steps from the Duquesne school which follows the Husserlian tradition and is a robust method for the researcher to find, understand, and describe the lived experience of the participants. The following steps were done: (1) Reading and rereading of transcripts, (2)extracting significant statements, (3) formulating meanings, (4) categorizing into cluster of themes and validating with original text, (5) describing, (6) returning to participants, and (7) incorporating any changes based on the participants' feedback.

\section{Research Rigor}

In this study, the researcher ensured the trustworthiness of the data and the results to establish the validity and rigor of the study. Hence, the researcher satisfied the following criteria, namely, credibility, transferability, dependability, and confirmability (Guba and Lincoln, 1989). Credibility establishes the capability of the study to measure what is intended and is a true or correct reflection of the social reality of the participants. There are many strategies to address credibility such as prolonged engagement, bracketing, and member checks which were used in this study. Transferability, on the other hand, relates to the ability of the findings to be transferred or relates to other contexts or settings. In doing qualitative research, one should remember that is specific to a particular context, so it is important to have "thick description" of the particular phenomenon and allowing the reader to assess whether the findings are transferable to their situation or not. Another criterion is dependability; it ensures that the process or method is described in sufficient detail to facilitate another researcher to repeat the work. Finally, confirmability is comparable to objectivity in quantitative studies. The aim of this is to minimize the investigator's bias by acknowledging researcher predispositions and doing bracketing. By adhering to the following criteria, the researcher believes that this study is done rigorously (Holloway, 2008; Korstjens and Moser, 2017; Shenton, 2004).

\section{Ethical Considerations}

Considering the use of resources and time to be spent by the informants, the study considered the following dimensions of research ethics in the whole duration of the study: (1) Informed consent, (2) vulnerability of research informants, (3) privacy and confidentiality of information, and (4) transparency.

\section{RESULTS AND DISCUSSION}

In terms of preparation, these science students just like other students had to prepare for the unknown and for a worst-case scenario. The instance of knowing that the school year would open online, these science students did personal preparations before their classes were to start. The preparations of these students for online physics learning were focused on technological resources and personal preparations. In the study on students' preparations, there were two core themes that emerged, namely, gathering of resources and establishing schema and learning environment. Preparations are essential for science students to respond to the demands of learning, as well as assure success in taking the course. This helps the students to equip themselves to stay connected in classes and connect the prior learning to the concepts of physics subject to be taken and anticipate the rigors of the course (Shafiei Sarvestani et al., 2019).

\section{Theme 1. Technological Preparations}

Since the school where the students were enrolled held both synchronous and asynchronous classes, students needed to ensure that their internet connection would be stable by subscribing to internet providers, buying prepaid WIFI modems, identifying places where signal for data connection was strong and some looked for places where PisoWifi were available. Many of these students also had to purchase different gadgets such as headphones, cellphones, and upgraded their personal computers and laptops to support the software needed for synchronous classes. An example from one of the participants:

I told my parents, Ma, we need to buy the globe WIFI plan, I also encourage my father to buy headphones because there are many distractions during online class because my sister is also having her lessons for grade 7... (PI)

Participant 5 also shared her struggles in looking for a strong signal within her area as a preparation for her online classes:

I am struggling to get a signal, sir, so what I did is that I looked around for some areas to find a better signal, so I walked a couple of hundred meters away from my home just to have my classes (P5)

In addition, Participant 7 shared that he bought a better gadget and subscribed to an internet provider as part of his preparations:

I had prepared my gadgets, so I purchased a better phone, and got a subscription from an internet service provider... (P7)

\section{Theme 2. Self-Preparation}

After a long lockdown, students had to prepare themselves for the opening of online classes especially for physics classes because they have considered it as one of the most difficult subjects, they would be taking. Part of the self-preparations of students was reviewing their past lessons which were related to the physics subject they would be taking in the upcoming semester, watch a video about the upcoming physics subject, and prepared their learning environments to avoid distractions so that they could focus on their learning. An example from one of the participants:

Self-preparation, I purchase my laptop, studied my notes, and watch different videos that would be needed as it is vital for the semester (P6) 
Another participant said:

...finding a place so that I will not be disturbed, I needed to have a conducive learning space...I watched video tutorials even before knowing that I will have this subject reflected to my class registration...(P3)

And participant 12 also said that:

I made a small room in our house into someplace that will be more conducive for my learning.

The participants shared in this study that the preparations were essential in the learning of physics using online platforms. In the study of Arrieta et al. (2020), preparations played a very important role to counter anticipated challenges in an online learning, some of the preparations included technological resources enhancement, personal and profession development. These preparations were not just for students, but it was also evident for both teachers and parents (Jan, 2020) which was also noted in this study as the participants mentioned that they have told their parents to provide technological support as they were taking online classes.

In terms of self-preparation, the participants commonly shared that they studied their lecture notes, watched tutorial videos before classes started, and prepared a conducive learning environment. In an online class, students have this tendency to do advance preparations for their subjects, especially the difficult one because they get challenged and cannot just relax knowing that things will not be easy (Gedera, 2014), especially in science courses such as physics. Jan (2020) highlighted that the learning environment preparations helped students to be motivated and have more focus in studying that is why a conducive environment transpired as one of these students' preparations.

\section{Theme 3. Challenges in Online Learning}

Even before the start of the school year 2020-2021 students had already anticipated the real challenges in this new normal in teaching and learning process. Some of these challenges were internet connection and participation. However, it was different when one personally experienced and encountered them. It was only after taking physics subjects as an online class, that some expected and unexpected challenges arose. These college science students encountered challenges that could be addressed in the next semester as well as when returning to a face-to-face instruction. They shared that these challenges around things such as network issues, topics for real laboratory work, time constraints, lack of motivation, distractions in home environment, and lack of interactions. As one participant clearly pointed out:

In the case of online class, sir, there are many distractions and also online makes it hard to listen really well when the connection is not that strong, the sound of teacher is choppy that makes you lose interest or motivation because you cannot understand what the teacher is saying... and there are time constraints in answering assessments or asking questions so your mind drifts away sometimes. (P6)
Another participant also shared about the challenge he had encountered regarding time constraints and limited interaction:

The biggest challenges that I have encountered are the key concepts are very hard to tackle in a very short amount of time and the interaction is limited due to the technological constraints. (P7)

On the conduct of physics laboratory instructions, another participant shared:

In an online class, sir, there's limited interaction, and then in doing laboratory class, the different apparatus cannot be manipulated personally so we have to study again, review again, and research some other resources. (P5)

In terms of distractions at home while learning, one participant lamented:

I study during nighttime when everybody is asleep and then during the day I focus on things like my lessons. (P1) This pandemic has brought lots of challenges to students and teachers in learning and teaching. It transpired that laboratory activities in a physical classroom can never be replaced by the virtual simulations in an online classroom. In the study conducted by Jan (2020), it was emphasized that the unavailability of actual learning resources and materials affects the learning of the students, it may result in less learning or no learning at all (Wang, 2020). Distractions at home remain a challenge too because the concentration or focus of the students is affected. According to Shafiei Shafiei Sarvestani et al. (2019) that in an E-learning environment, the surroundings or external factor should be conducive to foster learning. The role of time in learning is very important, according to the study of Blackmon and Major (2020) the more time being allotted to synchronous sessions the better the appreciation and learning of students, it is also imperative that the limited time or time constraints in learning especially in science subjects hinders the continuity of learning. Together with this limited time, the interaction between student-teachers and student-students becomes limited. Another challenge that has been encountered is about networks issues, this leads to lack incomplete sessions, misconceptions, disconnectivity, lack of motivation, and even failure (Jan, 2020; Gedera, 2014, Shafiei Sarvestani et al., 2019; Arrieta et al., 2020).

The challenges that surfaced in this study about the online learning of physics in this time of pandemic just simply explained that this trying time has taught us that every circumstance is unpredictable and we need to be ready to face challenges. Despite the students, teachers, and other stakeholders not having much time to prepare due to sudden outbreak, they still managed and subsequently learned that preparation is the key. There is no perfect preparation but we know that every plan is flexible depending on the need and situation, and as teachers this is our primary task to cater the needs of our learners in this pandemic. In the part of students, this is an eye opener that they should learn and possess different skills such as critical, problem-solving, and adaptability to survive to any crisis. Dhawan (2020) highlighted that 
educational institutions should build resilience systems to ensure that students have those skills to cope with different challenges.

\section{Theme 4. Learning Management and Learning Opportunities}

Despite the challenges, the students have experienced in these trying times, there was a silver lining in this crisis, especially in education. The students have managed and found many opportunities in online learning of physics subject. These college science students perceived online physics learning as flexible and convenient, exploration of more learning resources and ways of learning physics, realizing more opportunities for improvement, and maximizing the utilization of technology for learning. A participant shared about availability of resources in the web:

I can explore the problem through the use of internet... formulas can easily be access through the net and improve my understanding. (P1)

Another participant also said:

For me, sir, is that through online class we can maximize the different references, we learned to manage our time and lessons... (P4)

In terms of perceived opportunities and self-improvement, one student said:

I discovered something about my attitude, I study at night, and I learned to study more, practice more problems and since we are at our comfortable houses I can Google more problems to practice and watch videos in YouTube to understand the concepts. (P3)

Another participant said that online class enabled her to become a better version of her and move out from her shell:

Learning online physics is had a great impact for me, sir, because I have new knowledge where I can move out of my shell, I can learn new things and how I study my lesson. (P5)

Science students considered this online learning of physics as an opportunity to become better version of themselves in terms of technological capabilities, time management, and adaptation to the challenges of the times. Face-to-face delivery of instruction for learning is the comfort zone of students as well as of teachers, however, the current pandemic situation forced them to take the road less traveled. Online learning as a road to travel opens lots of opportunities to teachers and students (Arrieta et al., 2020) to make online teaching and learning better. It may prepare them when the world returns to a better normal that we used to have. Many studies found out that online learning can offer lots of opportunities, which can be observed today as most of the institutions switched to this modality. The stakeholders of education here in the country have been contented and never tried new modes of learning. This pandemic will be a new phase for online learning and will allow the stakeholders to appreciate the good side of e-learning. Educational technology (EdTech) has been taught to education students, and this situation is timely and relevant to let them experience firsthand what EdTech can contribute really and how it is utilized in an online platform to deliver instruction and try to think ways on how to improve the gray areas of the model (Dhawan, 2020).

In the study of Blackmon and Major (2012), students expressed that they perceived online learning as an opportunity to have autonomy in learning, learn to balance their family and personal responsibilities, and the opportunity to connect and collaborate with other peers which also transpired in this study. Even before the pandemic, there were already actions taken on teaching and learning through online modality, called blended learning. According to Arrieta et al. (2020), it was anticipated that this may be the future of education, and as a result of this pandemic, it forced everyone to go to online education. With this, blended learning is foreseen as a new normal in the post-COVID-19 pandemic education because of its flexibility, and it allows us to maximize positive functions of education (Dziuban et al., 2018).

\section{CONCLUSION}

The study revealed that science students prepared well for physics online classes despite the unknown path, they would be traversing. The students prepared personally by improving their technological resources and capabilities, their learning area at home, and equipped themselves by studying in advance and watching related topics to the subject that they will be taking. For some, their internet connection needed to be strengthened by looking for a better signal and service provider, and there were some gadgets that they had to purchase, while some upgraded their laptops to meet the requirements of the platform that would be used in this new virtual learning. In terms of learning environment, they prepared an area where they could not be disturbed and distracted when having their classes and focus on learning physics course. The advance studying was also done by the students to be ready and build their schema about the topics of the physics subject that they will be taking.

Regarding the challenges in online learning, they said that network issues, limited time for synchronous sessions in a week, lack of motivation, unconducive learning environment at home, and not performing actual laboratory experiments were the main issues they encountered. To address these challenges, the students said that they changed their perspectives to be more positive, re-reading, and accessing different resources from the internet such as simulations, videos that explained the lessons and additional reading materials, and studied at night when everybody was as sleep. In spite of the struggles of learning physics in an online class, these students saw an opportunity to manage their learning and improve themselves by exploring the internet with more ways and resources to learn physics better, an opportunity to improve their time management, and be adept to the different technological applications for learning.

Based on these findings, it is implied that science students' preparations really helped them to manage learning the 
physics course in this new normal set-up. However, despite the preparations, there were still challenges that surfaced such as unstable connections, distractions at home, and time constraints. The challenges were overcome by the students through adaptation to the learning needs, maximizing available resources online, and being optimistic which they perceived as the silver lining of this online class in physics. Thus, the college science students' experiences in this new normal classroom set up will transform them into a better science students and teachers in a real classroom and adapt to the new normal in education after COVID-19 pandemic is over.

\section{RECOMMENDATIONS}

In the future studies, it is recommended to explore the experiences of other students who are not majoring in science and students who are in another school to have a better description of the phenomena being studied.

\section{IMPLICATIONS}

This study can be used as a basis by government agencies to continue the online distance learning or flexible learning even in post-pandemic time. Furthermore, this would serve as a guide to the HEIs to revisit and improve the current pedagogies and instructional support to address gaps and maximize learning.

The shift in the delivery of all instruction required all stakeholders imagine what would happen to the Philippine education, to include science education at the tertiary level after the school year 2020-2021. Due to the unpredicted circumstance as well as the many things that may yet still to come, it would be better for graduates of senior high schools to be prepared. One way to prepare them would be for them to reflect on the experiences of these college science major who took an online physics course. The experiences of these students will enable them to understand the different scenarios, concerns, and learning opportunities to succeed in learning science in an online platform.

\section{REFERENCES}

Arrieta, G., Dancel, J., \& Agbisit, M.J. (2020). Teaching science in the new normal: understanding the experiences of junior high school science teachers. MIPA Journal of Education, 2(2), 146-162.

Blackmon, S., \& Major, C. (2012). Student Experiences in Online Courses: A Qualitative Synthesis. Vol. 3. Green-Wich, CT: Information Age Publishing, Inc. pp. 77-85.

CHED. (2020). Memorandum Order Numbers 4 and 5: Guidelines on the Implementation of Flexible Learning and Suspension of HEIs Operations. Commission on Higher Education. Available from: https:// ched.gov.ph/wp-content/uploads/cmo-no.-4-s.-2020-guidelines-on-theimplementation-of-flexible-learning.pdf

Clarke, S., Jensen, J., \& Rowe, E. (2008). The impact of clergy-perpetrated sexual abuse: The role of gender, development, and posttraumatic stress. Journal of Child Sexual Abuse, 17, 329-358.

Colaizzi, P.F. (1978). Psychological research as the phenomenologist view. In: Existential Phenomenological Alternatives for Psychology. New York: Plenum Press.

Contant, T.L., Tweed, L., Bass, J.E., \& Carin, A.A. (2018). Teaching Inquiry through Inquiry Based Instruction. London, United Kingdom: Pearson.

Cresswell, J.W. (2013). Research Design: Qualitative Approach, Quantitative and Mixed. Thousand Oaks, California: Sage.

Dhawan, S. (2020). Online learning: A Panacea in the time of Covid-19 crisis. Journal of Educational Technology Systems, 49(1), 5-22.

Dziuban, C., Graham, C.R., Moskal, P.D., Norberg, A., \& Sicilia, N. (2018). Blended learning: The new normal and emerging technologies. International Journal of Educational Technology in Higher Education, 15(1), 1-16.

Fjelstul, J. (2006). The Impact of Online Education on Academic Performance for Ladies Professional Golf Association Teaching and Club Professionals. Electronic Theses and Dissertations, 2004-2019. Available from: https://stars.library.ucf.edu/etd/760

Gedera, D.S.P. (2014). Students' experiences of learning in a virtual classroom. International Journal of Education and Development Using Information and Communication Technology (IJEDICT), 10(4), 93-101.

Gedera, D., Williams, J., \& Wright, N. (2015). Identifying factors influencing students' motivation and engagement in online courses. In: Koh, C., (Ed.), Motivation, Leadership and Curriculum Design, Berlin: Springer. pp. 13-23.

Goodall, J., Day, C., Lindsay, G., Muijs, D., \& Harris, A. (2005). Evaluating the Impact of Continuing Professional Development. Department for Education. Research Report, 659.

Guba, E.G., \& Lincoln, Y.S. (1989). Fourth Generation Evaluation Thousand Oaks, California: Sage Publications, Inc.

Holloway, I. (2008). A-Z of Qualitative Research in Healthcare. $2^{\text {nd }}$ ed. Oxford, United Kingdom: Blackwell.

Jan, A. (2020). A phenomenological study of synchronous teaching during COVID-19: A case of an international school in Malaysia. Social Sciences and Humanities Open, 2(1), 100084.

Korstjens, I., \& Moser, A. (2017). Series: Practical guidance to qualitative research. Part 4: Trustworthiness and publishing. European Journal of General Practice, 24, 120-124.

Lopez, V., \& Whitehead, D. (2013). Sampling data and data collection in qualitative research. In: Nursing and Midwifery Research: Methods and Critical Appraisal for Evidence-Based Practice. Maryland Heights, Missouri: Mosby. pp. 124-140.

Mercado, J. (2020). Development of laboratory manual in physics for engineers. International Journal for Science and Research, 9(10), 200-210.

Nwankwo, A.A. (2015). Students' Learning Experiences and Perceptions of Online Course Content and Interactions. Walden Dissertations and Doctoral Studies, No. 188. Available from: https://scholarworks. waldenu.edu/dissertations/188

Obbink, K., \& Wheeler, G. (1993). Teaching and Learning via the Network: National Teacher Enhancement Network. Network Coalition for Networked Information. Available from: https://www.cni.org/projects/ netteach/1993/prop33.html

Philippine Information Agency. (2020). Article under Distance Learning Modality. Available from: https://pia.gov.ph/news/ tags/distance-learning-modality

Rodriguez, M., Ooms, A., \& Montañez, M. (2008). Students' perceptions of online-learning quality given comfort, motivation, satisfaction, and experience. Journal of Interactive Online Learning, 7(2), 105-125.

Salamat, P., Ahmad, L., Bakht, G., \& Saifi, I. (2018). Effects of e-learning on students' academic learning at university level. Asian Journal of Social Sciences and Humanities, 2(2), 1-12.

Shafiei Sarvestani, M., Mohammadi, M., Afshin, J., \& Raeisy, L. (2019). Students' experiences of E-learning challenges: A phenomenological study. Interdisciplinary Journal of Virtual Learning Medical Science, $10(3), 1-10$.

Shenton, K. (2004). Strategies for ensuring trustworthiness in qualitative research projects. Education for Information, 22, 63-75.

Wang, Y. (2020). How does the Chinese Education System Cope with the Virus Outbreak Challenge? China Daily, 18 February. Available from: https://news.cgtn.com/news/2020-02-18/China-s-online-learningsector-thrives-amid-epidemic-ObnQfU8hfW/index.html [Last accessed on 2021 Apr 15].

Zhu, C., Kintu, M.J., \& Kagambe, E. (2013) Blended learning effectiveness: the relationship between student characteristics, design features and outcomes. International Journal Educational Technology High Education, 14, 7. 